\title{
SCREENING FOR BLOOD SUGAR LEVELS AMONG YOUNG ADULT MALES ATTENDING MEDICINE OPD AT MIMSH, MANDYA CITY, KARNATAKA, INDIA
}

\author{
Ramakrishna. S, Poornima. S, Shivakumar. K. M
}

1. Assistant Professor, Department of General Medicine, MIMS. Mandya.

2. Assistant Professor, Department of Community Medicine, MIMS. Mandya

3. Professor \& Head, Department of General Medicine, MIMS. Mandya.

\section{CORRESPONDING AUTHOR}

Dr. Poornima. S, M.B.B.S. M.D., D.N.B., \#75, Ganesh Krupa, 4th Main, 1 ${ }^{\text {st }}$ cross,

Kothanur Dinne, JP Nagar $8^{\text {th }}$ Phase, Bangalore-560076, Karnataka State. E-mail: docspoornima@gmail.com Ph: 00919964851880.

ABSTRACT: BACKGROUND: The number of young adults seeking care for diabetes related complications has been constantly on the rise in our hospitals. This fact prompted us to take up this study. OBJECTIVE: To screen all the young males aged between 20- 30 years attending medicine OPD at MIMSH, Mandya City, for blood sugar levels. METHODOLOGY: A descriptive study of 6 months duration was taken up at Medical College Hospital MIMS, Mandya. All the consenting adult males were subjected to screening by capillary blood prick using Glucometric Random Blood Sugar level (GRBS) using electronic glucometer (Accucheck active) and sensor comfort strips. RESULTS: 635 (95.84\%) males had normal blood sugar levels at the time of screening. However, 49 (7.16\%) had blood sugar levels above the normal. 32 (4.67\%) males had impaired blood sugar levels and 17 (2.48\%) had blood sugar levels in the diabetic range. The mean blood sugar levels were $101 \mathrm{mg} / \mathrm{dl}$ with a standard deviation of $19.73 \mathrm{mg} / \mathrm{dL}$. CONCLUSIONS: Screening for blood sugar levels among the young adult males has been effective in early detection of impaired sugar level and hence at increased risk of diabetes.

KEY WORDS: Screening, Impaired glucose tolerance, Diabetes mellitus, Young adults

INTRODUCTION: India has acquired the dubious distinction of being called "the diabetes capital of the world" [1]. The total number of people suffering from diabetes in India is 62.4 million. Another 77.2 million people are living with pre-diabetes. ${ }^{[2] . ~ T h i s ~ n u m b e r ~ h a s ~ i n c r e a s e d ~}$ by 11 million over the last one year [3]. One in every sixth adult Indian is a diabetic. Diabetes, once a disease of the people in their forties and fifties is now being diagnosed increasing among the younger age people [4]. The disease diabetes once thought to be the disease of the urban dwellers is now making its mark in a big way in the peri urban and rural areas [5], affecting every section of the population men, women, young and the old alike [6]. However, ever increasing number of young adults being newly diagnosed of diabetes or seeking care for diabetes related complication at our medical college hospital compelled us to take this study. This study aims at early detection and initiate of appropriate treatment for those detected of diabetes [7]. Also provide diabetes specific education and promote preventive measures for all the young adults aged between 20-30 years ${ }^{[8]}$ attending medicine OPD at MIMSH. 
OBJECTIVE OF THE STUDY: To screen the young adults aged between 20- 30 years attending medicine OPD at MIMSH, for impaired glucose tolerance and diabetes mellitus using the standard glucometer method.

METHODOLOGY: All the patients aged 20-30 years attending Medicine OPD on first unit days between 9 am and $4 \mathrm{pm}$ were asked to participate in the study. Those patients willing to give a written informed consent were enrolled for the study. A descriptive study was planned for a period of 6 months from June 2010 to November 2010. A total of 1156 young adults were eligible for the study, however, only 684 subjects consented to participate in the study. This paper presents the excerpts of the results of young adult males screened during the study. The results of screening young adult females have been analyzed separately to reduce the obvious selection bias as majority females in the age group 20-30 years attended obstetric and gynecology OPD. This paper presents results of of male subjects only.

The consenting subjects were subjected to screening of blood glucose level by glucometer method. A standardized glucometer with sensor comfort strips were used for the study. The glucometers used for the study were calibrated and standardized before the start of the study. A group of student volunteers were trained in the procedure of obtaining the capillary blood from the subjects. In order to standardize the procedure of capillary blood testing for blood sugar, reduce inter and intra observer bias, the student volunteers involved in the conduct of the study, had to take a test and completing the test successfully before being enrolled as volunteers.

Study subjects were patients aged between 20-30 years attending the medicine OPD for any medical condition / ailments. Random blood sugar levels were tested using the glucometric sensor comfort strips. A minimum of 3 hours had to be elapsed after the last meal (breakfast or Lunch) before subjecting the subject for glucometric blood sugar estimation. The results were complied and analyzed using Microsoft excel and epi info softwares.

Standardization of the glucometer and deciding the cut-off point for the purpose of screening of young adults during the study: On average, blood readings from Accuchek active were higher than laboratory plasma sugar estimation. However, the sensitivity of Accuchek active was $72 \%$. Specificity and positive predictive value of glucometer was $100 \%$. Negative predictive values of glucometers were approximately $95 \%$. Depending on the above, and on incorporation of correction factor, the cut-off levels for screening were worked out. In this screening study, $<142 \mathrm{mg} / \mathrm{dL}$ as normal, $143 \mathrm{mg} / \mathrm{dL}$ to $161 \mathrm{mg} / \mathrm{dL}$ as Impaired glucose tolerance level and > $162 \mathrm{mg} / \mathrm{dL}$ for diabetes mellitus. However, all the subjects in the abnormal sugar levels were called for fasting oral glucose challenge test and the results were confirmed.

ETHICAL CLEARANCE: The study has obtained institutional ethical committee approval.

RESULTS: A total of 1156 male subjects were eligible to participate in the study. However, only $684(58.71 \%)$ males consented to participate in the study. The average age of the subjects was 23.53 years. Lack of time and fear of prick were the most common reasons given by those now willing to participate in the study.

$73(10.67 \%)$ of the subjects were illiterate. $173(25.39 \%)$ subjects had completed primary education, 165 (24.12\%) high school, 134 (19.59\%) college, 116 (16.95\%) had bachelor's degree and 23 (3.36 \%) had a master's degree. 
$171(14.68 \%)$ subjects were students not involved in any income producing activities, 116 (16.95\%) subjects were manual laborers, 227 (33.18\%) were involved in clerical work, 159 (23.24\%) were involved in semiprofessional work like tailoring, driving, garment factory worker etc and 11(1.60\%) were professions like lawyers, doctors or engineers.

Modified BG Prasad's socio-economic status classification was used for assessment of socio-economic status of the subjects. Majority subjects 307 (44.88\%) belonged to class III, 112 $(16.37 \%)$ to class IV, $136(19.88 \%)$ class II, 94(13.74\%) to class I and 35 (5.11\%) belonged to class V.

$182(26.60 \%)$ subjects gave history of at least one of their family member or a first degree relative, suffering from diabetes mellitus.

Table 1: Distribution of screening results of subjects according to blood sugar levels $(\mathrm{N}=684)$

\begin{tabular}{|c|c|}
\hline $\begin{array}{c}\text { Accuchek glucometer } \\
\text { capillary glucose values }\end{array}$ & $\begin{array}{l}\text { Number of males subject } \\
\mathbf{( \% )}\end{array}$ \\
\hline $\begin{array}{c}\text { <142mg/dL } \\
\text { Normal }\end{array}$ & $635(92.84 \%)$ \\
\hline $\begin{array}{c}\mathbf{1 4 3 - 1 6 1 m g / d L} \\
\text { Imparied glucose levels }\end{array}$ & $32(4.68 \%)$ \\
\hline $\begin{array}{c}\text { >162mg/dL } \\
\text { Diabetes mellitus }\end{array}$ & $17(2.48 \%)$ \\
\hline Mean $\pm \mathbf{2}$ SD in mg / dL & $101 \pm 39.46$ \\
\hline Total & $684(100.00 \%)$ \\
\hline
\end{tabular}

$635(95.84 \%)$ subjects had normal glycemic levels at the time of screening and 49 subjects $(7.16 \%)$ had blood sugar levels above the normal. Of the subjects with abnormal sugar levels, 32 (4.67 \%) had impaired glucose tolerance and 17 (2.46\%) had blood sugar levels in the diabetic range. The mean blood glucose levels were $101 \mathrm{mg} / \mathrm{dL}$, with a standard deviation was $19.73 \mathrm{mg} / \mathrm{dL}$.

The subjects with abnormal sugar levels were invited for a confirmatory Oral Glucose Tolerance Test (OGTT). 12 subjects agreed to undergo OGTT. 8 subjects were confirmed to be having impaired glucose tolerance and 4 subjects OGTT results were normal. The subjects attending the same were given diabetes specific health education and put on nonpharmacological therapy.

Of the 17 subjects diagnosed to be diabetic by the screening test, 15 of them were confirmed of diabetes. These subjects were put on pharmacological therapy for diabetes. However, 2 subjects had very high values of blood sugar by screening and were found to be normal on repeat test.

The average weight of the subjects was calculated to be 63.87 kilograms and average height was $169.05 \mathrm{cms}$. The average waist hip ratio was 0.89 . 
CONCLUSION: The yield of screening for blood sugar levels using capillary finger prick blood at the OPD, among the young adult males has shown moderate success in early detection of subjects with impaired and higher glycemic levels. Capillary finger prick blood method with electronic glucometer is a less invasive method for screening for early diabetes, requirement of trained manpower, cost of the procedure, were challenges we encountered. However, a yield of $7.16 \%$ abnormal sugar levels among the young adult males aged $20-30$ years (study subjects) is a matter of grave concern. Authors recommend that every available outlet like waiting place at the OPD, waiting time in the OPD queue is used to dissemination appropriate Information, education and communication (IEC) for a healthy lifestyle among the young adults, including facilities for early screening for diabetes. This move can help early diagnosis, appropriate treatment and prevention of complications due to diabetes.

FUNDING: The study was taken up as a part of regular academic research activity funded by the Government of Karnataka through the Medical College Hospital funds.

CONFLICT OF INTEREST: None.

ACKNOWLEDGEMENTS: The Director, Medical Superintendent, Faculty and Staff of department of General Medicine and Community Medicine, MIMS, Mandya, Karnataka.

\section{REFERENCES:}

1. World Health Organization. Prevalence of diabetes in the WHO South-East Asia Region.Availablefrom:http://www.who.int/diabetes/facts/world_figures/en/index5.ht $\mathrm{ml}$ [Accessed July 22, 2009, $2.10 \mathrm{pm}$ ].

2. Prevalence of diabetes and pre-diabetes in India. ICMR-INDIAB study: new figure of diabetes. The Hindu. National-news column: Special Correpondent; Chennai; Sep 29: 2011.

3. WHO technical report series 916. (2003) Diet, nutrition, and the prevention of excess weight gain and obesity. Report of a joint WHO/ FAO expert consultation. Geneva: WHO. Available online as of $\quad 7 / 1 / 2007$ at: http://www.who.int/hpr/NPH/docs/who_fao_expert_report.pdf

4. Mendez M, Popkin BM. (2004) Globalization, urbanization and nutritional change in the developing world. Journal of Agricultural and Development Economics.

5. Popkin, Barry. (2002) Stages of the Nutrition Transition: Dynamic Global Shifts Appear to be Accelerating. Available online as of 5/7/2008 at:http://www.sne.org/conference/documents/BarryPopkinNutritionTransition.pdf.

6. Mohan D, Raj D, Shanthirani CS, Datta M, Unwin NC, Kapur A, et al. Awareness and knowledge of diabetes in Chennai - The Chennai Urban rural Epidemiology study. J Assoc Physicians India. 2005; 53:283-7. [PubMed]

7. Lau SL, Debarm R, Thomas N, Asha HS, Vasan KS, Alex RG, et al. Healthcare Planning in North-East India: A Survey on Diabetes Awareness, Risk Factors and Health Attitudes in a Rural Community. J Assoc Physicians India. 2009; 57:305-9. [PubMed]

8. Pereira MA, Kartashov AI, Ebbeling CB, Van Horn L, Slattery ML, Jacobs DR Jr et al. Fastfood habits, weight gain, and insulin resistance (the CARDIA study): 15-year prospective analysis. Lancet. 2005; Jan 1-7;365(9453):36-42. available online as on 20-09-11 http://www.ncbi.nlm.nih.gov/pubmed/15639678 